\title{
Medullary epidural hematoma as a complication of thrombolysis in a patient with myocardial infarction
}

\section{Hematoma epidural medular como complicación de trombólisis en un paciente con infarto del miocardio}

\author{
Meredith Agüero-Castrellón ${ }^{1 *}$, Fernando M. Calderón-Osorio", Josué B. Zamarripa-Mottú2, \\ Nundehui Cisneros-Sánchez¹, Luis A. Sierra-Rodríguez'1, and José M. Meza-Alvarado ${ }^{1}$
}

${ }^{1}$ Department of Clinical Cardiology; ${ }^{2}$ Department of Hemodynamics and Interventionism. High Specialty Medical Unit No. 71, Instituto Mexicano del Seguro Social, Torreón, Coahuila, Mexico

Thrombolytic therapy is one of the strategies for ST-segment elevation acute myocardial infarction reperfusion. Among its complications, hemorrhage stands out, with an incidence of major hemorrhage of up to $8 \%{ }^{1}$. The Acute Coronary Syndromes National Registry (RENASICA II - Registro Nacional de Síndromes Coronarios Agudos II) indicates an incidence of major hemorrhage of between $1 \%$ and $2 \%{ }^{2}$.

It is difficult for real incidence to be established due to the heterogeneity of major bleeding definitions ${ }^{3}$. RENASICA III defines major bleeding as fatal bleeding, documented retroperitoneal bleeding, intracranial or intraocular bleeding, bleeding resulting in hemodynamic compromise that requires specific treatment, bleeding requiring surgical treatment or decompression of an enclosed space to control the event, any transfusion $>1$ unit of packed red blood cells or whole blood, hemoglobin drop $>3 \mathrm{mg} / \mathrm{dL}$ or hematocrit drop $>10 \%{ }^{4}$.

Predisposing factors for bleeding include clinical, pharmacological and invasive procedure-related parameters, out of which those with the highest impact are age, female gender, history of bleeding and anemia, kidney failure, presentation with cardiogenic shock, use of invasive procedures and treatment with glycoprotein Ilb/Illa inhibitors ${ }^{3}$.

\section{Clinical case}

Sixty five-year-old man with a history of high blood pressure, social drinking, smoking, sedentary lifestyle and obesity. He attended the emergency department for typical chest pain. 12-lead electrocardiogram documented the diagnosis of ST-segment elevation myocardial infarction, with thrombolytic therapy with tenecteplase therefore being administered. Since criteria for reperfusion were not met, the patient was referred to our hemodynamics unit for rescue percutaneous coronary intervention, where he referred with cervical pain upon admission. Anterior descending artery angioplasty was successfully performed and surveillance continued at the coronary care unit, with the patient subsequently being discharged to the cardiology hospitalization area. During the first hours, neurological manifestations were added to the pain, with rapid sensory and motor deterioration in all four extremities until complete medullary syndrome was developed. Magnetic resonance imaging (MRI) revealed an intra-spinal lesion with cervical spinal cord compression associated with an epidural hematoma at C2-C5 (Fig. 1). He

\section{Correspondence:}

*Meredith Agüero-Castrellón

E-mail: mere21_06@ hotmail.com
Date of reception: 07-02-2020

Date of acceptance: 16-06-2020

DOI: 10.24875/ACME.M21000205
Available online: 19-07-2021

Arch Cardiol Mex (Eng). 2021;91(2):223-225 www.archivoscardiologia.com 2604-7063 / @ 2020 Instituto Nacional de Cardiología Ignacio Chávez. Published by Permanyer. This is an open access article under the CC BY-NC-ND license (http://creativecommons.org/licenses/by-nc-nd/4.0/). 


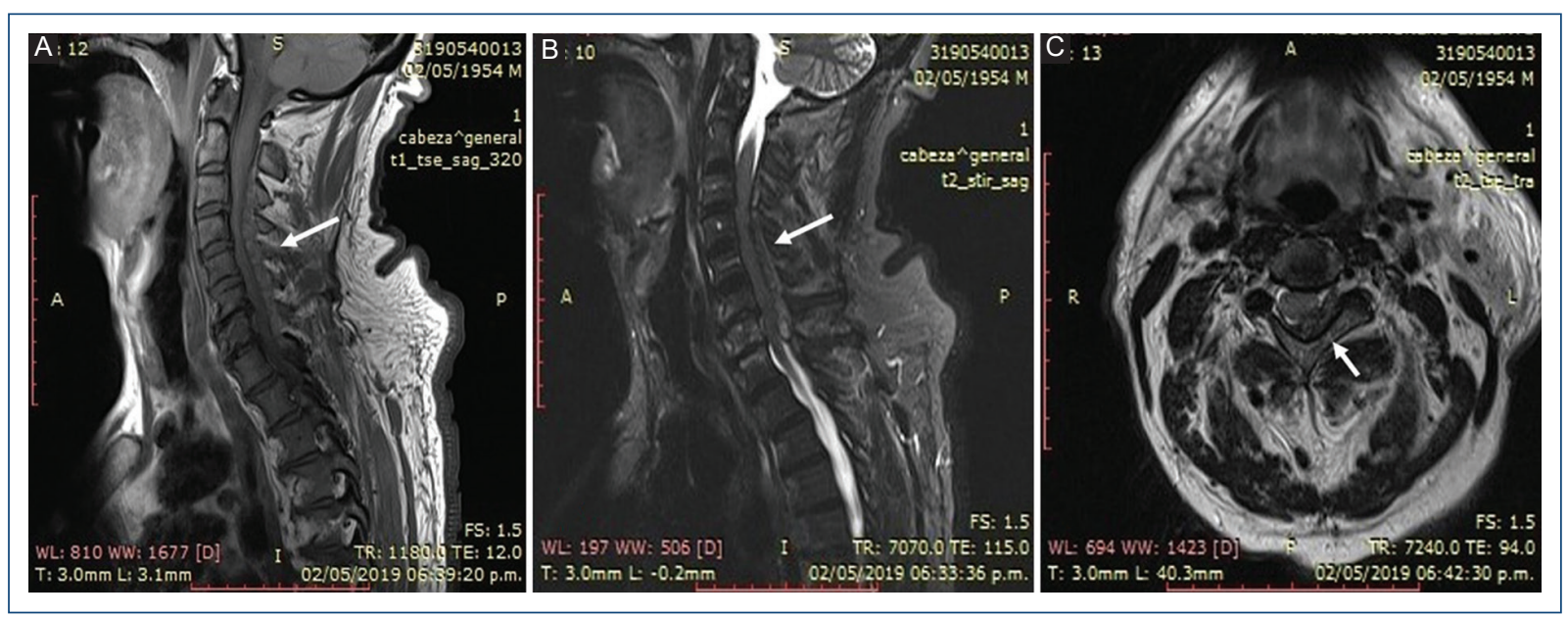

Figure 1. Cervicothoracic spine MRI sagittal section images showing a lesion in the spinal canal extending from $\mathrm{C} 2$ to C5 (arrows). A: T1-weighting. B: T2-weighting. C: cross-section at the C3 level, T2-weighted image, showing a hypointense area with medullary compression effect in relation to a hematoma.

developed hemodynamic and respiratory deterioration requiring support with norepinephrine and endotracheal intubation. Cervical decompressive laminectomy at C6 was performed, with the patient remaining under surveillance in the intensive care unit and subsequently in the cardiology area, where he continued to evolve positively. Finally, he was discharged with left hemiplegia as a sequel.

\section{Discussion}

The incidence of thrombolysis-associated major hemorrhage has been reported to be $6.3 \%$ for streptokinase, $5.4 \%$ for alteplase and $4.7 \%$ for tenecteplase 1 . The ASSENT-2 trial showed that tenecteplase was associated with a lower major hemorrhage rate than alteplase $(4.7 \text { vs. } 5.9 \% ; p=0.0002)^{1,5}$.

Spontaneous epidural hematoma incidence is estimated to be $0.1 \%$; it is associated with trauma, coagulopathy, arteriovenous malformations, tumors or infections. There are no statistics on the incidence of spontaneous epidural hematoma associated with fibrinolytic treatment owing to its low frequency, but some cases secondary to the use of tissue plasminogen activator have been reported ${ }^{6,7}$.

In case of spinal hematoma, symptom onset is generally sudden and with rapid progression. Typically, patients present with severe cervicalgia and signs of medullary compression. Diagnosis is confirmed by $\mathrm{MRI}$, and treatment is with surgical decompression of the spinal canal ${ }^{6}$.
Prognosis depends on the level of involvement and evolution time ${ }^{6}$. Post-surgical improvement occurs in $95 \%$ of incomplete sensorimotor lesions and in $45 \%$ of lesions with complete sensorimotor loss ${ }^{7}$.

\section{Conclusions}

Medullary hematoma as a complication of thrombolysis is extremely rare. It should be suspected in the presence of cervical or dorsal pain after thrombolysis. Early recognition and MRI confirmation are crucial for timely treatment to be established and for prognosis to be improved.

\section{Acknowledgements}

To all staff physicians and resident physicians of the departments of clinical cardiology, hemodynamics and interventionism, clinical neurology, imaging, neurosurgery and intensive coronary and adult care unit involved in the timely care and resolution of this case.

\section{Funding}

No funding of any kind was received for this work.

\section{Conflicts of interest}

The authors declare that they have no conflicts of interest. 


\section{Ethical disclosures}

Protection of human and animal subjects. The authors declare that no experiments have been performed on humans or animals for this research.

Confidentiality of data. The authors declare that no patient data appear in this article.

Right to privacy and informed consent. The authors declare that no patient data appear in this article.

\section{References}

1. Echavarría M, Juárez U, Meillón L, Martínez C. Complicaciones hemorrágicas del tratamiento de los síndromes coronarios agudos. Arch Cardiol Mex. 2011;81:228-39.
2. García A, Jerjes C, Martínez P, Azpiri JR, Autrey A, Martínez C, et al. RENASICA II Registro Mexicano de Síndromes Coronarios Agudos. Arch Cardiol Mex. 2005;75:S6-S19.

3. Sánchez M, Manzano S, Valdes M. ¿Por qué debemos estratificar el riesgo hemorrágico junto con el isquémico en el síndrome coronario agudo? Rev Esp Cardiol Supl. 2014;14(A):10-7.

4. Jerjes C, Martínez C, Borrayo G, Carrillo J, Juárez U, Quintanilla J. Third national registry of acute coronary syndromes (RENASICA III). Arch Cardiol Mex. 2015;85:207-14

5. Assessment of the Safety and Efficacy of a New Thrombolytic (ASSENT-2) Investigators, Van De Werf F, Adgey J, Ardissino D, Armstrong PW, Aylward P, Barbash G, et al. Single-bolus tenecteplase compared with front-loaded alteplase in acute myocardial infarction: the ASSENT-2 double-blind randomised trial. Lancet. 1999;354:716-22.

6. Salehpour F, Mirzaei F, Kazemzadeh M, Alavi SAN. Spontaneous epidural hematoma of cervical spine. Int J Spine Surg. 2018;12:26-9.

7. Sawin PD, Traynelis VC, Follett KA. Spinal epidural hematoma following coronary thrombolysis with tissue plasminogen activator. Report of two cases. J Neurosurg. 1995;83:350-3. 